\section{Screening for Powdery Mildew Resistance in Pulmonaria}

\author{
Kimberly H. Krahl ${ }^{1}$ \\ Department of Landscape Architecture and Horticulture, Temple University, \\ 480 Meetinghouse Road, Ambler, PA 19002
}

\begin{abstract}
Additional index words. lungwort, Bethlehem sage, powdery mildew disease, Pulmonaria angustifolia, Pulmonaria longifolia, Pulmonaria officinalis, Pulmonaria rubra, Pulmonaria saccharata
\end{abstract}

\begin{abstract}
A screening technique was developed for studying resistance to powdery mildew disease in 25 diverse Pulmonaria L. species and cultivars. Healthy Pulmonaria plants were inoculated by drawing naturally infected leaves of $P$. angustifolia 'Blaues Meer' across the abaxial surface of three healthy, mature leaves per test plant. Inoculated leaves were rated for powdery mildew infection using a scale of $0-5$, where $0=$ no visible sign of infection, $1=1 \%$ to $20 \% ; 2=20 \%$ to $40 \% ; 3=40 \%$ to $60 \% ; 4=60 \%$ to $80 \% ; 5=80 \%$ to $100 \%$ of leaf surface covered with white mycelial growth. Each genotype was inoculated and evaluated four times. The data revealed a wide and continuous range of variability for powdery mildew disease incidence in the 25 lungwort genotypes that may be indicative of quantitative resistance. The majority of lungwort genotypes exhibited low levels of resistance to powdery mildew. Four cultivars $(P$. hybrid 'Spilled Milk', $P$. hybrid 'Excaliber', $P$. rubra 'Redstart', and $P$. rubra 'David Ward') and one selection ( $P$. longifolia ssp. cevennensis) exhibited high levels of resistance to powdery mildew. Since Pulmonaria species intercross readily, these genotypes may be useful in the future development of new powdery mildew resistant Pulmonaria cultivars.
\end{abstract}

Lungworts are outstanding spring-blooming ornamental plants native to Europe and Asia belonging to the genus Pulmonaria. While these excellent plants have been utilized in European and Asian gardens for many years, the American gardening public has become fully aware of the outstanding ornamental qualities of Pulmonaria species and cultivars fairly recently. Lungworts brighten the spring garden with their blue, pink, coral-red, or white flowers. Although lungworts provide attractive early floral color in the spring garden, they are grown primarily for their ornamental foliage. Many lungwort species and cultivars sport foliage that is dramatically spotted and splotched with silver and white. Lungworts are excellent, easily grown shady garden groundcovers, lighting up darker corners of the garden with their variously spotted and blotched foliage throughout the growing season(Lovejoy, 1993; Mathew, 1982). Although there are $\approx 12$ species of Pulmonaria, only four species are commonly used horticulturally: $P$. angustifolia, $P$. longifolia, $P$. rubra, and $P$. saccharata. Lungwort species hybridize freely and many of the most popular cultivars are presumed to be interspecific hybrids (Armitage, 1997).

Lungworts are generally quite tough garden plants, thriving when provided with a few simple cultural requirements: adequate

Received for publication 19 Nov. 2002. Accepted for publication 28 Apr. 2003. I thank the Perennial Plant Association, Hilliard, Ohio, for funding this research and Roslyn Gorin, Temple Univ., for statistical support.

${ }^{1}$ To whom reprint requests should be addressed. Current address: 699 Rheas Mill Rd., Farmington, AR 72730; e-mail: kimkrahl@yahoo.com moisture, good drainage, and partial shade. However, many lungwort cultivars and selections are quite susceptible to powdery mildew disease.

Powdery mildews are among the most common and widespread of the fungal plant diseases, affecting an extremely wide range of plants, from grasses to tree species. Powdery mildew is caused by many different species of fungi belonging to the Erysiphaceae family. The species of fungus causing powdery mildew disease in lungworts has yet to be identified. Powdery mildew fungi are obligate polycyclic parasites, overwintering as cleistothecia on living or dead plant tissue. Powdery mildew disease is typified by the appearance of patches of whitish mycelial growth on plant surfaces. Heavily infected plants can become entirely covered with the whitish "powder" of thick mycelial growth. Not only does powdery mildew disease greatly decrease the ornamental value of affected plants, but it also has detrimental physiological effects. Infected plants may exhibit dwarfing and stunting, reddenflower buds (Agrios, 1997). Powdery mildew decreases photosynthesis due to the thick felt produced by intertwining fungal mycelia on leaf surfaces and inhibits plant growth due to withdrawal of plant storage food by the fungus (Agrios, 1997).

Powdery mildew spores germinate under conditions of high humidity (commonly produced at the leaf surface as cool nights change to warm days), when plants are crowded or grown in shady environments without adequate air circulation. These environmental conditions are typical in the shade garden and thus predispose lungworts to infection by powdery mildew fungi. The disease is ing and curling of leaves, and deformation of more prevalent and severe in areas with high relative humidity and periodic drought conditions. Water-stressed plants are usually the first to show symptoms of powdery mildew disease (Agrios, 1997).

Although variation for resistance to powdery mildew has been noted (Armitage, 1997; DiSabato-Aust, 1998), no controlled study has been conducted to evaluate lungwort species and cultivars for resistance to powdery mildew. If genetic resistance to powdery mildew can be identified in lungwort, the potential exists to develop new cultivars with powdery mildew resistance.

\section{Materials and Methods}

Twenty-five lungwort cultivars and selections were screened for resistance to powdery mildew in the Temple Univ. greenhouse in Ambler, Pa., during Summer 2001. All plants were grown in 15 -cm-diameter plastic pots in a soilless medium (ProMix B, Premier Horticulture, Quebec, Canada) in a completely random design. Plants were watered as needed with a $120 \mathrm{mg} \cdot \mathrm{L}^{-1} \mathrm{~N}$ solution of $20-10-20$ soluble fertilizer. Plants of $P$. angustifolia 'Blaues Meer' were maintained separately in the greenhouse and allowed to develop powdery mildew disease naturally. Heavily infected leaves of $P$. angustifolia 'Blaues Meer' were used to inoculate test plants. Three test plants per genotype were inoculated by gently drawing naturally infected leaves of $P$. angustifolia 'Blaues Meer' across the abaxial surface of three healthy, mature leaves (total of nine leaves inoculated each test date). After 3 weeks, inoculated plants were evaluated for powdery mildew development. Development of whitish mycelial growth on the leaf surface was defined as powdery mildew infection. Inoculated leaves were rated for powdery mildew infection using a scale of $0-5$, where $0=$ no visible sign of infection; $1=1 \%$ to $20 \% ; 2=$ $20 \%$ to $40 \% ; 3=40 \%$ to $60 \% ; 4=60 \%$ to $80 \%$; $5=80 \%$ to $100 \%$ of leaf surface covered with white mycelial growth. Three different plants of each cultivar or selection were treated and evaluated four times (four replications) during Summer 2001.

Mean ratings for powdery mildew resistance were analyzed using Proc ANOVA, with multiple comparisons determined using Duncan's multiple range test (SAS Institute, Cary, N.C.). Spearman's correlation coefficients were calculated to assess consistency of genotype rank order over testing dates.

\section{Results and Discussion}

Analysis of variance revealed significant differences for resistance to powdery mildew among the 25 lungwort genotypes (Table 1). The genotype $\times$ date term was significant and thus was used as the error term in the analysis of variance. Although a significant interaction occurred between genotype and testing date, the estimate of the variance component for genotype was almost 9.8 times greater than the variance component for genotype $\times$ date, indicating that the contribution of testing date in 
Table 1. Analysis of variance for powdery mildew disease incidence for 25 Pulmonaria genotypes.

\begin{tabular}{lrc}
\hline Source & df & MS \\
\hline Genotype $^{z}$ & 24 & $29.12^{* * *}$ \\
Date & 3 & 0.18 \\
Genotype $\times$ date & 72 & $0.90^{* * *}$ \\
Error & 200 & 0.19 \\
\hline
\end{tabular}

${ }^{2}$ Genotype $\times$ date is the error term for testing genotype effect.

"*** Significant at $P=0.001$.

Table 2. Species, cultivar, and mean rating for powdery mildew disease incidence for 25 Pulmonaria genotypes.

\begin{tabular}{|c|c|}
\hline Genotype $^{z}$ & Mean rating ${ }^{y}$ \\
\hline P. longifolia Golden Haze & $4.67 \mathrm{a}^{\mathrm{x}}$ \\
\hline P. angustifolia Blaues Meer & $4.56 \mathrm{a}$ \\
\hline P. longifolia E.B. Anderson & $4.50 \mathrm{a}$ \\
\hline P. saccharata Roy Davidson & $4.50 \mathrm{a}$ \\
\hline$P$. hybrid Majeste & $4.31 \mathrm{a}$ \\
\hline P. saccharata Dora Bielefeld & $4.14 \mathrm{ab}$ \\
\hline$P$. hybrid Ocupol (Opal) & $4.08 \mathrm{ab}$ \\
\hline P. longifolia Bertram Anderson & $4.00 \mathrm{abc}$ \\
\hline$P$. hybrid Merlin & $3.89 \mathrm{a}-\mathrm{d}$ \\
\hline P. officinalis Sissinghurst White & $3.89 \mathrm{a}-\mathrm{d}$ \\
\hline$P$. hybrid Smokey Blue & $3.31 \mathrm{~b}-\mathrm{e}$ \\
\hline P. saccharata Pierre's Pure Pink & $3.17 \mathrm{c}-\mathrm{e}$ \\
\hline P. vallarsae Marjorie Fish & $3.11 \mathrm{de}$ \\
\hline P. saccharata Mrs. Moon & $3.08 \mathrm{de}$ \\
\hline$P$. hybrid Coral Springs & 2.83 ef \\
\hline$P$. hybrid Milky Way & $2.64 \mathrm{ef}$ \\
\hline P. officinalis White Wings & $2.5 \mathrm{efg}$ \\
\hline P. saccharata British Sterling & $2.11 \mathrm{fg}$ \\
\hline$P$. longifolia Dordogne & $1.78 \mathrm{~g}$ \\
\hline$P$. hybrid Raspberry Splash & $1.75 \mathrm{~g}$ \\
\hline$P$. hybrid Spilled Milk & $0.42 \mathrm{~h}$ \\
\hline$P$. hybrid Excaliber & $0.39 \mathrm{~h}$ \\
\hline P. rubra Redstart & $0.25 \mathrm{~h}$ \\
\hline P. rubra David Ward & $0.11 \mathrm{~h}$ \\
\hline P. longifolia subsp. cevennensis & $0.00 \mathrm{~h}$ \\
\hline
\end{tabular}

${ }^{2}$ Nomenclature as per Hoffman et al., 2000.

${ }^{y}$ Mean rating based on a scale of $0-5: 0=$ no visible sign of infection; $1=1 \%$ to $20 \% ; 2=20 \%$ to $40 \% ; 3$ $=40 \%$ to $60 \% ; 4=60 \%$ to $80 \% ; 5=80 \%$ to $100 \%$ of leaf surface covered with white mycelial growth.

'Mean separation by Duncan's multiple range test, $P=0.05 ; \mathrm{n}=3$ for each genotype.

the genotypic expression for powdery mildew resistance was small.

The data revealed a wide and continuous range of variability for infection and development of powdery mildew disease in the 25 lungwort genotypes (Table 2). The continuous range of variability suggests that resistance to powdery mildew in lungworts may be quantitative. Spearman's correlation coefficients among testing dates were significant (ranging from $r=0.77$ to 0.89 ), indicating relatively high levels of genotype rank order consistency among testing dates (ranging from 59\% to 79\% rank order consistency among dates). The majority of lungwort genotypes in this study exhibited mid to high mean ratings for powdery mildew infection, indicating relatively low levels of resistance to powdery mildew. However, four cultivars ('Spilled Milk', 'Excaliber', 'Redstart', and 'David Ward') and one selection (P. longifolia ssp. cevennensis) exhibited mean ratings for powdery mildew infection of less than 1.00 , indicating high levels of resistance to powdery mildew. For these five genotypes the majority of inoculated leaves never developed any visible signs of infection and when infection did occur, less than $20 \%$ of the leaf surface showed evidence of powdery mildew mycelial growth. The lungwort selection P. longifolia ssp. cevennensis showed no visible sign of infection throughout the entire study, suggesting that this selection has very high levels of resistance to powdery mildew. In this study, the single representative of the species $P$. angustifolia, the cultivar 'Blaues Meer', exhibited a very high mean rating (4.56) for powdery mildew development, indicating a very low level of resistance to powdery mildew. The two representatives of the species $P$. rubra, the cultivars 'Redstart' and 'David Ward', exhibited very low mean ratings for powdery mildew infection $(0.25$ and 0.11 , respectively), indicating high levels of resistance to powdery mildew. (It would be interesting to examine whether other cultivars of $P$. angustifolia and $P$. rubra would also exhibit these respective low and high levels of resistance.) Lungwort genotypes with $P$. longifolia parentage exhibited the extremes of resistance from high to low. While the selection $P$. longifolia ssp. cevennensis exhibited the lowest mean rating $(0.00)$ or highest resistance of all the genotypes tested, another P. longifolia cultivar, 'Golden Haze', exhibited the highest mean rating (4.67) of all tested genotypes, indicating extremely low resistance to powdery mildew. Pulmonaria longifolia 'Dordogne' and $P$. hybrid 'Raspberry Splash', which is purported to be a P. longifolia hybrid (Armitage, 1997), also exhibited relatively low mean ratings (1.78 and 1.75 , respectively), indicating moderately high levels of resistance to powdery mildew. Lungworts with $P$. saccharata parentage exhibited the entire range of variability for resistance to powdery mildew. Five of the 10 lungwort cultivars with a mean rating over 3.50 , indicating very low levels of resistance, are of known or purported $P$. saccharata parentage ('Roy Davidson', 'Majeste', 'Dora Bielefeld', 'Opal', and 'Merlin') (Armitage, 1997; Hoffman et al., 2000). Conversely, two of the five lungwort genotypes exhibiting a mean rating of less than 1.00 , indicating very high levels of resistance, are purported to be $P$. saccharata hybrids ('Spilled Milk' and 'Excaliber') (Ar- mitage, 1997).

The five lungwort genotypes exhibiting mean ratings of less than 1.00 , indicating very high levels of powdery mildew resistance, represent three different Pulmonaria species ( $P$. longifolia, $P$. rubra, and $P$. saccharata), demonstrating that useful sources of genetic resistance are not restricted to any particular species. Additionally, these five lungwort genotypes represent quite a range of variability for ornamental attributes. Cultivars of P. rubra, such as 'Redstart', typically have coral-red flowers and unspotted foliage. Pulmonaria rubra 'David Ward' has the additional ornamental value of sporting leaves that are almost mint green in color with a distinct white margin. 'Spilled Milk', purported to be a $P$. saccharata hybrid (Armitage, 1997), has heavily splotched foliage and pink flowers. Pulmonaria hybrid 'Excaliber', also purported to be a P. saccharata hybrid (Armitage, 1997), has leaves that are almost solid silver with a thin green margin and rose-colored flowers. Pulmonaria longifolia ssp. cevennensis, a selection from Cevennes, France, has long, narrow, heavily spotted leaves, vigorous growth, and deep violet-blue flowers. Other than the cultivar David Ward, which is purported to be sterile (S. Cooperman, Crown Oak Nursery, Downingtown, Pa., personal communication), this group of lungwort genotypes may provide useful sources of genetic resistance to powdery mildew. Since Pulmonaria species intercross readily, these resistant genotypes may be useful to introgress powdery mildew resistance into diverse lungwort germplasm that may have high ornamental value but little powdery mildew resistance. The future is bright for the development of new powdery mildew resistant lungwort cultivars with all the ornamental attributes we now enjoy in this fabulous genus.

\section{Literature Cited}

Agrios, G.N. 1997. Plant disease caused by fungi. In: Plant pathology. Academic Press, New York.

Armitage, A.M. 1997. Pulmonaria. In: Herbaceous perennial plants. Stipes Publ. Co., Champaign, Ill.

DiSabato-Aust, T. 1998. Encyclopedia of perennials. In: The well-tended perennial garden. Timber Press, Portland, Ore.

Hoffman, M.H.A., H.J. van de Laar, G. Fortgens, and P.C. de Jong. 2000. List of names of perennials. Appl. Res. for Nursery Stock, Boskoop, the Netherlands.

Lovejoy, A. 1993. Pulmonarias. Horticulture 71: $54-58$.

Mathew, B. 1982. Pulmonaria in gardens. The Plantsman 4:100-111.

SAS Institute, 2001. Release 8.2. SAS Inst., Cary, N.C. 